\title{
Price Elasticities of Charitable Giving across Donation Sectors in Canada: Is the Tax Incentive Effective?
}

\author{
Belayet Hossain and Laura Lamb \\ Department of Economics, Thompson Rivers University, 900 McGill Road, Kamloops, BC, Canada V2C 0C8 \\ Correspondence should be addressed to Belayet Hossain, bhossain@tru.ca
}

Received 15 November 2012; Accepted 4 December 2012

Academic Editors: M. T. Leung and K. P. Upadhyaya

Copyright ( $) 2012$ B. Hossain and L. Lamb. This is an open access article distributed under the Creative Commons Attribution License, which permits unrestricted use, distribution, and reproduction in any medium, provided the original work is properly cited.

The effectiveness of tax incentives on charitable donation expenditures in Canada is explored, and the analysis is extended to compare the effectiveness across different donation sectors. Price elasticities are estimated with data from the 2007 Canada Survey of Giving, Volunteering and Participating. Results suggest that specific charitable sectors are affected differently by Canada's tax credit system. The findings have implications for public policy.

\section{Introduction}

As do most governments of developed nations, the Canadian government provides a tax incentive to encourage charitable giving. There is a healthy body of literature assessing the effectiveness of tax incentive policies on charitable giving [1-10], although few Canadian studies have compared the effectiveness across the different donation sectors. The current research attempts to fill this void by exploring two facets of the effectiveness of tax incentives on charitable giving in Canada. First, it evaluates the effectiveness of tax incentives on an individual's total donation expenditure. Second, the analysis is broadened to assess and compare the effectiveness of tax incentives across four donation sectors.

Much of the existing literature is grounded in the assumption that the responsiveness of charitable giving expenditures to tax incentives is equivalent across all donation sectors, except for two studies on donation expenditures in the U.S. $[2,5]$ and one in Taiwan [4]. To our knowledge, this assumption has not been tested for Canadian donation expenditures, except for Hossain and Lamb [1] who examined the effectiveness of tax policy on the decision to donate across donation sectors, and Kitchen and Dalton [11] and Kitchen [12] who explored the effectiveness of tax policy on donation expenditures to the religious sector.
This study tests two hypotheses. The first hypothesis is that a change in the price of the donation will affect an individual's total donation expenditure. The second hypothesis is that the effectiveness of the tax incentive varies across donation sectors, as revealed by price elasticities. Among the past studies, there is no clear consensus on how price elasticities of charitable donations vary among the different sectors. Kitchen [12] found the demand for total charitable giving in Canada to be price elastic but price to have no effect on religious giving. Brooks [2] reported total donations and donations to the health sector to be price inelastic, and donations to the religious, education and social welfare sectors to be price elastic in the U.S. while Chang [4] found total donations as well as donations to all specific donation sectors to be price elastic in Taiwan.

The purpose of this research is to inform public policy decisions. For instance, if tax incentives are effective for some sectors and not others, then direct government support rather than tax credits may be a more appropriate method of providing the goods and services of those sectors. The remainder of the paper is organized as follows. Section 2 consists of a description of the methodology including the model, econometric techniques for analysis, data, and variables. Section 3 is a discussion of the empirical results followed by a discussion of policy implications and a conclusion in Section 4. 


\section{Methodology}

Past studies on charitable giving expenditures have considered an array of socioeconomic variables, such as gender, age, education, income, number of dependents, marital status, employment status, after-tax price of donation, volunteer status, and religious status [3-5]. This study includes those variables plus geographic influences, as was done in previous Canadian studies $[11,12]$. In addition, it has been suggested that attending religious meetings and immigrant status may be relevant variables $[1,14]$.

The proposed determinants of charitable donation expenditures are organized into three categories: economic, sociodemographic, and geographic. The economic factors include household income, price of donation, and employment status. The price of donation is the key variable of interest in the model, as its estimated value will determine the effectiveness of Canadian tax policy on charitable giving expenditures. The results of testing the two hypotheses will indicate whether and to what extent the current tax policy is effective at generating contributions to charitable and nonprofit organizations in Canada.

The sociodemographic characteristics include age, gender, marital status, education, religious attendance, presence of children, country of birth, and participation in volunteer activities. The geographic factors include regional specific influences as defined by the following five regions: British Columbia, the Prairies, Ontario, Quebec, and the Atlantic region.

The Canadian Survey of Giving, Volunteering and Participating [13] categorizes registered charitable and nonprofit organizations into twelve sectors according to the International Classification of Nonprofit Organizations. The current analysis covers the following four largest donation sectors, according to the value of total donations, in descending order: religious, health, social services, and international. It is noted that potential overlap between charitable donation sectors poses a limitation to this analysis. For instance, religious organizations often allocate funding to social services and international aid.

Since 1988, tax incentives for charitable giving have been provided to Canadian tax payers through a tax credit system, different from the more common tax deduction system. Under the deduction system, the value of the tax benefit depends on the donor's level of income whereas, under the credit system, the value of the benefit depends on the total amount of charitable donations claimed in the particular tax year [15]. The Canadian tax credit system is a two-tier system such that there are two levels of tax credits at both the federal and provincial levels, one for annual donation expenditures of up to $\$ 200$ and a higher one for the annual amount of donation expenditure over $\$ 200$.

2.1. Econometric Model. Each of the two hypotheses is tested with an econometric model. The first model (1) tests the effectiveness of tax incentives on total charitable expenditures and a second model (2) compares the effectiveness across four charitable donation sectors.

$$
D_{i}= \begin{cases}f\left(X_{i}, Z_{i}, G_{i}\right), & \text { if DS }=g\left(X_{i}, Z_{i}, G_{i}\right)>0, \\ 0, & \text { otherwise }\end{cases}
$$

where $D_{i}$ represents the total donation expenditure made by the $i$ th individual; $X_{i}$ is the vector of economic variables applicable to the $i$ th individual, which includes the price of donation; $Z_{i}$ is the vector of all sociodemographic characteristics relevant to the $i$ th individual; $G_{i}$ is the vector of variables relating to the region of residence of the $i$ th individual; DS is the donor status, which is 1 (donor) or 0 (nondonor).

$$
D_{i j}= \begin{cases}f\left(X_{i}, Z_{i}, G_{i}\right), & \text { if } \mathrm{DS}=g\left(X_{i}, Z_{i}, G_{i}\right)>0, \\ 0, & \text { otherwise, }\end{cases}
$$

where $D_{i j}$ is the donation expenditure by the $i$ th individual to the $j$ th charitable sector; $j$ can be 1 to 4 , representing each of the four sectors under study.

Note that the estimation of both models requires the inclusion of all people irrespective of whether or not the individual made a charitable donation. Each donor may make more than one donation and may donate to more than one charitable sector.

In both models (described by (1) and (2)) the dependent variable, $D_{i}$ or $D_{i j}$, is observed only if a respondent makes a donation. Consider $U_{i}$ to be the unobserved utility an individual receives when making a donation. $U_{i}$ is expected to be determined by the set of variables, $X_{i}, Z_{i}$, and $G_{i}$, although we do not observe $U_{i}$. We observe a dichotomous variable DS, the donor status, with a value 1 if the respondent is a donor $\left(U_{i}>0\right)$ and zero otherwise, referred to as the selection equation. The error terms in both parts of each model are expected to be correlated. However, if the selection equation is omitted, the parameter estimates of the donation expenditure equations will be biased and inconsistent. Since the donors are self-selected and thereby do not comprise a random sample, the error will not be distributed normally. For example, the preference for making a donation to a particular organization is higher for donors than for the general population. The Heckman selection model is appropriate for addressing this issue of selection bias [8].

Heckman's selection model is a two-step procedure. In the first step, the selection equation is estimated by the maximum likelihood approach (MLE), and the inverse Mills ratio $\left(\hat{\lambda_{i}}\right)$ is then estimated with the MLE parameter estimates. In the second step, $\hat{\lambda}_{i}$ is included along with all other explanatory variables to estimate $D_{i}$ or $D_{i j}$. Adding $\hat{\lambda}_{i}$ as a regressor results in the problem of hetroskedasticity which is resolved by using robust standard errors. Thus, the Heckman selection model estimates both the donation expenditure and donation status simultaneously in order to address possible selection bias and is used for each model.

2.2. Data and Variables. The study uses data from the 2007 Canada Survey of Giving, Volunteering and Participating 
published by Statistics Canada. The target population is all persons 15 years of age or over living in the ten provinces. After the variables for the models are identified, observations with missing values are excluded from the analysis, leaving 18457 observations for analysis. Table 1 presents frequency and percentage distributions of sample member characteristics of those who make charitable donations. The summary of donation expenditure by sector and price of donation are shown in Table 2.

The economic, sociodemographic, and geographic characteristics are listed and described in Table 3 . The price of donation is a measure of the price per dollar of the donation expenditure after the tax incentive is considered. For each sample member, the price can be considered to be equal to one minus the tax credit, which is determined by their donation expenditure and the federal and provincial tax credit rates. However, given that this measurement of price is determined by the amount of donation expenditure, the variable would be endogenous and would result in inconsistent estimates of the two models. A proxy variable is used to overcome the endogeneity issue, as was used in Hossain and Lamb [1] (Instrument variables are typically used to address the problems associated with endogenous variables; however, the sample selection model does not allow for the use of instrument variables.). It is calculated as one minus the sum of the federal and provincial marginal income tax rates for each sample member, based on the median of the sample member's personal income bracket. The donation expenditure and the proxy for price of donation are measured in natural logarithms in order to interpret the coefficients as elasticities.

\section{Empirical Results}

The results of the two models are illustrated in Table 4. The reported results are the marginal effects of the explanatory variables on donation expenditures. Note that model 1 estimates the total donation expenditure while model 2 estimates the donation expenditure for each of the four charitable donation sectors.

Overall, the specifications of all models are found to be robust, as evidenced by the Wald statistic. In line with the a-priori expectation, the coefficient for price of donation is both negative and significant for total donation expenditures as well as for each of the four donation sectors. In fact, among all the variables for all five equations, price of donation has the largest marginal effect on donation expenditures.

The estimated price elasticity of total donations is -1.68 , implying that a 10 cent (or 10\%) decrease in price of donation (or increase in the tax incentive) increases the total donation expenditure by close to 17 cents (or 17\%). For the donation sectors, the price elasticity varies between -0.81 for religious donations and -2.21 for international donations. All price elasticities are elastic, except for religion, suggesting that a marginal increase in the tax credit will result in a proportionately larger increase in the level of donations for total donation expenditures and for the health, social service,
TABLE 1: Frequency and percentage distributions of sample members characteristics who make charitable donations $(n=16,565)$.

\begin{tabular}{|c|c|c|c|}
\hline Variables & Category & Frequency & $\%$ \\
\hline $\begin{array}{l}\text { Participation in } \\
\text { charitable giving }\end{array}$ & & 16,565 & $89.7 \%$ \\
\hline \multirow{3}{*}{ Household income } & $<\$ 60000$ & 8,379 & $50.6 \%$ \\
\hline & $\$ 60000-\$ 100000$ & 4,445 & $26.8 \%$ \\
\hline & $\$ 100000+$ & 3,741 & $22.6 \%$ \\
\hline \multirow{3}{*}{ Age } & $15-34$ & 3,762 & $22.7 \%$ \\
\hline & $35-54$ & 6,710 & $40.5 \%$ \\
\hline & $55+$ & 6,093 & $36.8 \%$ \\
\hline \multirow[b]{2}{*}{ Education } & $\begin{array}{l}\text { Maximum high } \\
\text { school diploma }\end{array}$ & 4,817 & $29.1 \%$ \\
\hline & $\begin{array}{l}\text { Some post- } \\
\text { secondary/diploma to } \\
\text { university degree }\end{array}$ & 11,748 & $70.9 \%$ \\
\hline \multirow{2}{*}{ Gender } & Female & 9,596 & $57.9 \%$ \\
\hline & Male & 6,969 & $42.1 \%$ \\
\hline Born in Canada & & 14,330 & $86.5 \%$ \\
\hline Marital status & Married & 9,852 & $59.5 \%$ \\
\hline Preschool children & $\geq 1$ & 1,943 & $11.7 \%$ \\
\hline School age children & $\geq 1$ & 4,201 & $25.4 \%$ \\
\hline \multirow{5}{*}{ Regions } & Atlantic & 4,183 & $25.3 \%$ \\
\hline & Quebec & 3,051 & $18.4 \%$ \\
\hline & Ontario & 3,061 & $18.5 \%$ \\
\hline & Prairies & 3,838 & $23.2 \%$ \\
\hline & British Columbia & 2,432 & $14.7 \%$ \\
\hline Religious attendance & $\geq$ Weekly & 5,649 & $31.1 \%$ \\
\hline Employment status & Employed & 10,621 & $64.1 \%$ \\
\hline Volunteer status & Participate & 11,328 & $68.4 \%$ \\
\hline
\end{tabular}

Source: [13].

TABLE 2: Summary of donation and price statistics for sample members who make charitable donations $(n=16,565)$.

\begin{tabular}{lcc}
\hline Variable & Mean & Standard deviation \\
\hline Total charitable donations & $\$ 544.87$ & 1376.78 \\
Religious donations & $\$ 261.94$ & 928.92 \\
Health donations & $\$ 100.12$ & 382.57 \\
Social service donations & $\$ 51.24$ & 316.22 \\
International donations & $\$ 34.77$ & 329.97 \\
Price of donation & 0.70 & 0.07 \\
\hline
\end{tabular}

Source: [13].

and international sectors. And the amount of the tax revenue forgone will be less than the rise in donation expenditures for all sectors except religion.

Estimated price elasticities in this study are in the same range as those of other studies in USA and Canada, as illustrated in Table 5. Using 1982 Canadian household expenditure survey data Kitchen and Dalton [11] estimated the price elasticity of total donations to be -1.07 , while Kitchen [12] with 1984 Canadian household expenditure survey data found the price elasticity to be -2.29 . This study's estimate of price elasticity for total donation expenditures 
TABLe 3: Description of variables.

\begin{tabular}{|c|c|c|}
\hline Categories & Variable name & Description of the variable \\
\hline \multirow{5}{*}{ Economic } & Price of donation & The price per dollar of donation \\
\hline & Income & (Base category: less than $\$ 60000$ ) \\
\hline & Income 1 & If respondent has household income from $\$ 60000$ to $\$ 100000$, then 1 ; otherwise 0 \\
\hline & Income 2 & If respondent has household income more than $\$ 100000$, then 1 ; otherwise 0 \\
\hline & Employed & If the respondent is employed, then 1 ; otherwise 0 \\
\hline \multirow{11}{*}{ Sociodemographic } & Age & (Base category: age $15-34$ ) \\
\hline & Age 1 & If respondent's age is between 35 years and 55 years, then 1 ; otherwise 0 \\
\hline & Age 2 & If respondent's age is greater than 55 years, then 1 ; otherwise 0 \\
\hline & High education & If respondent has postsecondary education, then 1 ; otherwise 0 \\
\hline & Male & If respondent is male, then 1 and 0 for female \\
\hline & Married & If respondent is married, then 1 ; otherwise 0 \\
\hline & Religious & $\begin{array}{l}\text { If respondent attends religious gathering or meetings at least once a week, then } 1 \text {; } \\
\text { otherwise } 0\end{array}$ \\
\hline & Canadian born & If respondent is born in Canada, then 1 ; otherwise 0 \\
\hline & Preschool children & If respondent's household has preschool age children, then 1 ; otherwise 0 \\
\hline & School age children & If respondent's household has school age children, then 1 ; otherwise 0 \\
\hline & Volunteer & If respondent participates in volunteer activities, then 1 ; otherwise 0 \\
\hline \multirow{5}{*}{ Geographic } & Regions & (Base category: Ontario) \\
\hline & Quebec & If the respondent is a resident of Quebec, then 1 ; otherwise 0 \\
\hline & Atlantic & If the respondent is a resident of Atlantic, then 1; otherwise 0 \\
\hline & Prairies & If the respondent is a resident of Prairies, then 1 ; otherwise 0 \\
\hline & British Columbia (BC) & If the respondent is a resident of $\mathrm{BC}$, then 1 ; otherwise 0 \\
\hline
\end{tabular}

TABLE 4: Average marginal effects for total donation expenditures and by sector.

\begin{tabular}{|c|c|c|c|c|c|}
\hline Variable & Total donation & Religion & Health & Social services & International \\
\hline Price of donation & $-1.677 * *(0.187)$ & $-0.814^{* *}(0.332)$ & $-1.490 * *(0.170)$ & $-1.710^{* *}(0.249)$ & $-2.205^{* *}(0.504)$ \\
\hline Age1 & $0.636^{* *}(0.049)$ & $0.551^{* *}(0.097)$ & $0.375^{* *}(0.046)$ & $0.491^{* *}(0.007)$ & $0.511^{* *}(0.145)$ \\
\hline Age2 & $1.183^{* *}(0.056)$ & $1.088^{* *}(0.122)$ & $0.761^{* *}(0.053)$ & $0.809^{* *}(0.080)$ & $0.629^{* *}(0.174)$ \\
\hline High education & $0.421^{* *}(0.044)$ & $0.173^{*}(0.086)$ & $0.291^{* *}(0.039)$ & $0.243^{* *}(0.054)$ & $0.294(0.163)$ \\
\hline Income 1 & $0.193^{* *}(0.051)$ & $0.200 *(0.087)$ & $0.218^{* *}(0.046)$ & $0.046(0.060)$ & $0.171(0.139)$ \\
\hline Income 2 & $0.591 * *(0.054)$ & $0.225^{*}(0.097)$ & $0.608^{* *}(0.054)$ & $0.382^{* *}(0.075)$ & $0.301(0.164)$ \\
\hline Religious attendance & $0.066^{* *}(0.012)$ & $0.037^{* *}(0.004)$ & $0.054^{* *}(0.008)$ & $0.062 * *(0.011)$ & $0.069(0.014)$ \\
\hline Employed & $0.117^{* *}(0.013)$ & $0.028^{* *}(0.004)$ & $0.079^{* *}(0.009)$ & $0.079^{* *}(0.012)$ & $0.083^{* *}(0.017)$ \\
\hline Married & $0.149^{* *}(0.043)$ & $0.091(0.081)$ & $-0.001(0.039)$ & $-0.170 * *(0.056)$ & $0.155(0.120)$ \\
\hline Canadian born & $-0.071(0.058)$ & $-0.080(0.087)$ & $0.146^{* *}(0.048)$ & $0.026(0.069)$ & $-0.277^{* *}(0.114)$ \\
\hline Male & $-0.108^{* *}(0.039)$ & $0.009(0.071)$ & $-0.110^{* *}(0.036)$ & $-0.064(0.051)$ & $0.013(0.123)$ \\
\hline Volunteer & $0.208^{* *}(0.008)$ & $0.061^{* *}(0.003)$ & $0.128^{* *}(0.006)$ & $0.142 * *(0.008)$ & $0.183^{* *}(0.012)$ \\
\hline Preschool children & $0.154^{* *}(0.063)$ & $0.114(0.104)$ & $-0.051(0.052)$ & $0.158 *(0.075)$ & $0.281 *(0.148)$ \\
\hline School age children & $-0.124 * *(0.045)$ & $-0.094(0.077)$ & $-0.220 * *(0.041)$ & $-0.141^{* *}(0.056)$ & $-0.471^{* *}(0.127)$ \\
\hline Quebec & $-0.676^{* *}(0.049)$ & $-1.456^{* *}(0.082)$ & $-0.557 * *(0.048)$ & $-0.414^{* *}(0.063)$ & $-0.489^{* *}(0.168)$ \\
\hline Atlantic & $-0.107^{*}(0.052)$ & $-0.159(0.088)$ & $-0.381^{* *}(0.045)$ & $-0.143^{*}(0.062)$ & $-0.084(0.186)$ \\
\hline Prairies & $0.105^{*}(0.055)$ & $0.245^{* *}(0.094)$ & $-0.093 *(0.046)$ & $0.260 * *(0.068)$ & $0.412 * *(0.145)$ \\
\hline British Columbia & $0.197 * *(0.065)$ & $0.528^{* *}(0.117)$ & $0.114 *(0.058)$ & $0.584^{* *}(0.080)$ & $0.480^{* *}(0.145)$ \\
\hline Wald statistic & 173.03 & 0.443 & 61.74 & 36.31 & 2.72 \\
\hline Rho & $-0.606(0.034)$ & $-0.094(0.142)$ & $-0.432(0.048)$ & $-0.363(0.055)$ & $-0.221(0.129)$ \\
\hline
\end{tabular}

(1) Robust standard errors are reported in parentheses.

(2) $* *$ indicates the level of significance at less than 0.05 and $*$ indicates the level of significance at less than 0.1 level.

(3) The estimates of the Heckman sample selection model are significantly superior to those of the standard tobit model (at 0.05 levels) for all equations except religion and international donation expenditures, as demonstrated by the Rho statistics. Accordingly, religion and International equations are estimated with a tobit model. 
TABLE 5: Comparison of price elasticities of donation expenditure estimates across similar studies.

\begin{tabular}{lcccccc}
\hline Studies/authors & All sectors & Religion & Health & Social services & Education & International \\
\hline Present study (Canada) & -1.68 & -0.81 & -1.49 & -1.71 & - & -2.21 \\
Brooks (USA, 2007) [2] & -2.70 & -1.16 & -0.58 & -1.33 & -1.21 & - \\
Chang (Taiwan, 2005) [4] & -5.25 & -6.32 & -1.38 & -4.99 & -3.36 & - \\
Kitchen and Dalton (Canada, 1990) [11] & -1.07 & -2.37 & - & - & - & - \\
Kitchen (Canada, 1992) [12] & -2.29 & - & - & - & - & - \\
\hline
\end{tabular}

TABLE 6: Hypothesis tests of the equivalence of price elasticities of donation expenditures.

\begin{tabular}{|c|c|c|c|c|c|}
\hline \multirow{2}{*}{ Hypothesis: equivalent elasticity among sectors } & \multicolumn{5}{|c|}{ Level of significance } \\
\hline & Total donation & Religion & Health & Social service & International \\
\hline Unit elasticity & $* * *$ & $\mathrm{X}$ & $*$ & $*$ & $*$ \\
\hline Elasticity for total donation expenditures & & $* * *$ & $* * *$ & $* * *$ & $* * *$ \\
\hline Elasticity for religious donation expenditures & & & $* * *$ & $* * *$ & $* * *$ \\
\hline Elasticity for health donation expenditures & & & & $* * *$ & $* * *$ \\
\hline Elasticity for social service donation expenditures & & & & & $* * *$ \\
\hline
\end{tabular}

All hypothesis test results are chi-square results. The null hypothesis of unit price elasticity is rejected for total donation expenditure and for each sector, except religion where the elasticity is indistinguishable from one. The null hypothesis of equivalent elasticity is rejected for total donations and across all sectors.

$\mathrm{X}$ : statistically indistinguishable. ${ }^{* *}$ indicates statistically distinguishable at the .01 level and $*$ indicates distinguishable at the 0.10 level.

lies in between the two previous Canadian studies. In contrast to the two previous Canadian studies, the present paper finds the price elasticity of donations to religious organizations to be negative and significant, but inelastic. The present results are relatively closer to those of Brooks [2] than those of Chang [4], not surprising given the relatively strong similarities between Canadian and US economies and cultures, as compared with those of Taiwan.

Hypothesis test results, in Table 6, illustrate that all price elasticities are statistically distinguishable from the value of one (unit elasticity), except for the religious sector where elasticity is not different from unit elasticity. Price elasticities are also statistically distinguishable from one another, providing support for the hypothesis that the responsiveness of charitable donations to tax incentives varies across the different charitable sectors.

Among the other economic characteristics, household income and employment are positive and significant. As expected household income has a positive effect on total donation expenditures and on donation expenditures for religion, health, and social services. Individuals with household income in the range of $\$ 60000$ to $\$ 100000$ are likely to donate more to religious and health sectors than those with household incomes less than $\$ 60000$. Similarly, those with household income greater than $\$ 100000$ are likely to donate more than those with household incomes in the range of $\$ 60000$ to $\$ 100000$, to all donation sectors, except international ones. Being employed has a positive impact on donation expenditures, irrespective of donation sector. Most of the sociodemographic characteristics have a significant impact on total donation expenditures as well as on the four sectors. Age has a positive and significant effect on total donations as well as on each of the four sectors.

Female respondents are more likely to make larger total donations and health donations than males. The results imply that gender does not have a significant effect on the amount of donations to religion, social services, or international organizations. Married respondents are more likely to make larger total donations and larger donations to the social service sector than those not married. An individual with at least some postsecondary education is likely to contribute more to each donation sector, except international ones, than an individual with a maximum education of high school graduation. Individuals born in Canada donate more to health organizations than immigrants, but immigrants donate more to international organizations than those born in Canada. Participation in volunteer activities significantly increases total donation expenditures as well as to all four donation sectors as compared to those who do not volunteer. Attending weekly religious services or meetings also tends to increase total donations as well as for each sector, except for international.

The presence of preschool children in the household is associated with larger total donation expenditures as well as larger expenditures to social service and international organizations compared to individuals without preschool children. On the other hand, the presence of school age children tends to decrease total donation expenditures and expenditures to health, social service, and international organizations relative to those without school age children.

Four regional dummy variables are used to assess the effect of the geographic regions on total donations, with Ontario being the reference region. Other things being equal, the residents of Quebec and the Atlantic regions donate less than the residents of Ontario, and the residents of the Prairies and British Columbia donate more than those of Ontario (The coefficients for the regional variables are found to be significantly different from each other at the .05 level.).

\section{Policy Implications and Conclusion}

The empirical results suggest that tax incentives have a significant effect on charitable donation expenditures, implying 
the ability of public policy to affect changes in the level of donation expenditures in Canada. The tax credit appears to be fiscally efficient (Fiscal efficiency as it relates to tax incentives is defined as the case where an increase in donation expenditures is greater than the loss of tax revenue due to the tax incentive [2].), as indicated by elastic demand for charitable donations. An increase in the tax credit is expected to lead to a loss of tax revenue to the public sector which would be more than fully compensated by the rise in donation expenditures. Donations to religious organizations are not price elastic suggesting that the tax credit may not be fiscally efficient for the religious sector. Given that Canadians tend to donate to more than one charitable sector, on average the tax credit system for charitable donations can be considered to be fiscally efficient.

The significance of volunteering suggests that donating and volunteering are complements rather than substitutes. It may be the case that participating in volunteer activities raises awareness of the importance of the goods and services provided by charities and non-profits resulting in larger financial donations. The recognition of this relationship suggests that governments can indirectly encourage donations through the support of volunteer activities.

Given the distinguishable price elasticities for each of the four charitable sectors, there are concerns about policy decisions made under the assumption that all donation sectors are equally affected by the tax credit. For instance, an increase in the tax credit is expected to lead to a rise in international donations more than social service donations, health, and religious organizations. These results inevitably lead to normative discussions about which types of organizations provide the goods and services most valued by society. Public policy could be used to tailor tax credit rates to reflect society's preferences and needs by setting unique tax credit rates for the different donation sectors. For example, if the goods and services provided by social services donations are valued more highly than those provided by religious organizations, the tax credit rate for social service donations could be increased and/or reduced for religious donations.

In sum, both provincial and federal governments have the ability to influence charitable donation expenditures by adjusting the tax credit rates. Government also has the ability to influence the expenditure levels of specific types of donations by setting individual tax credit rates for each sector for the purpose of encouraging the provision of public goods and services most valued by society. In addition, the results indicate international donations to be most responsive to potential changes in tax credits and religious giving to be least responsive, thereby suggesting the need for policy makers to be cognizant of the varying levels of responsiveness of each sector to potential changes in tax incentives.

\section{References}

[1] B. Hossain and L. Lamb, "Does the effectiveness of tax incentives on the decision to give charitable donations vary across donation sectors in Canada?" Applied Economics Letters, vol. 19, no. 15, pp. 1487-1491, 2012.
[2] A. C. Brooks, "Income tax policy and charitable giving," Journal of Policy Analysis and Management, vol. 26, no. 3, pp. 599612, 2007.

[3] J. Carroll, S. McCarthy, and C. Newman, "An econometric analysis of charitable donations in the Republic of Ireland," Economic and Social Review, vol. 36, no. 3, pp. 229-249, 2005.

[4] W. C. Chang, "Determinants of donations: empirical evidence from Taiwan," Developing Economies, vol. 43, no. 2, pp. 217234, 2005.

[5] N. E. Feldman and J. R. Hines Jr., "Tax credit and charitable contributions in Michigan," Working Paper, University of Michigan, Ann Arbor, Mich, USA, 2003.

[6] J. Peloza and P. Steel, "The price elasticities of charitable contributions: a meta-analysis," Journal of Public Policy and Marketing, vol. 24, no. 2, pp. 260-272, 2005.

[7] G. E. Auten, H. Sieg, and C. T. Clotfelter, "Charitable giving, income, and taxes: an analysis of panel data," American Economic Review, vol. 92, no. 1, pp. 371-382, 2002.

[8] I. García and C. Marcuello, "A household model of charitable contributions and tax incentives," Annals of Public and Cooperative Economics, vol. 72, no. 2, pp. 159-181, 2001.

[9] A. Jones and J. Posnett, "Charitable Donations by UK households: evidence from the family expenditure survey," Applied Economics, vol. 23, pp. 343-351, 1991.

[10] C. T. Clotfelter, Federal Tax Policy and Charitable Giving, NBER, 1985.

[11] H. Kitchen and R. Dalton, "Determinants of charitable donations by families in Canada: a regional analysis," Applied Economics, vol. 22, pp. 285-299, 1990.

[12] H. Kitchen, "Determinants of charitable donations in Canada: a comparison over time," Applied Economics, vol. 24, pp. 709713, 1992.

[13] Statistics Canada, Canada Survey of Giving, Volunteering and Participating (CSGVP), Public Use Microdata File, 2007.

[14] Statistics Canada, Caring Canadians, Involved Canadians: Highlights From the 2007 Canada Survey of Giving, Volunteering and Participating, Statistics Canada, Ottawa, Canada, 2009.

[15] D. Duff, "Charitable contribution and the personal income tax: evaluating the canadian credit," in Between State and Market: Essay on Charities Law and Policy in Canada, J. Phillips, B. Chapman, and D. Stevens, Eds., McGill-Queen's University Press, 2001. 


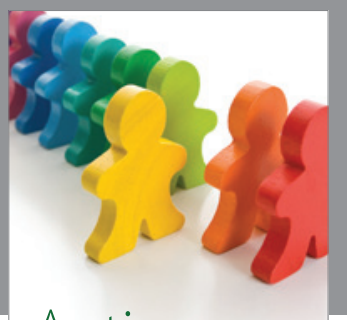

Autism

Research and Treatment
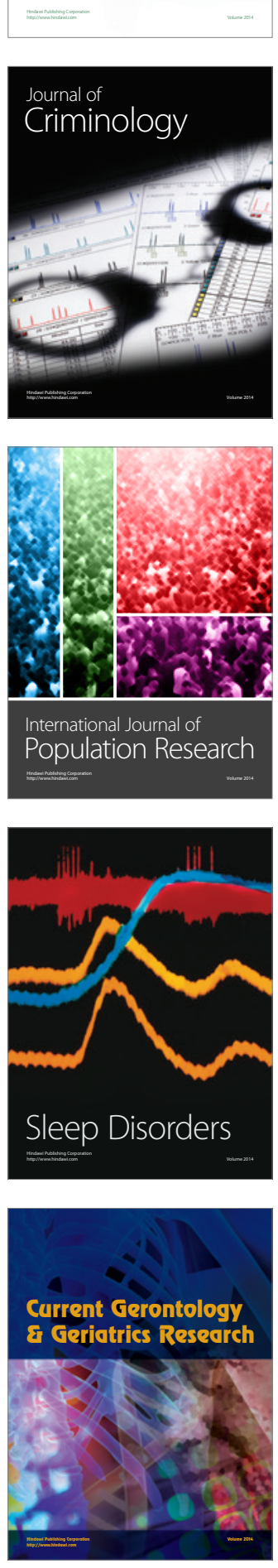
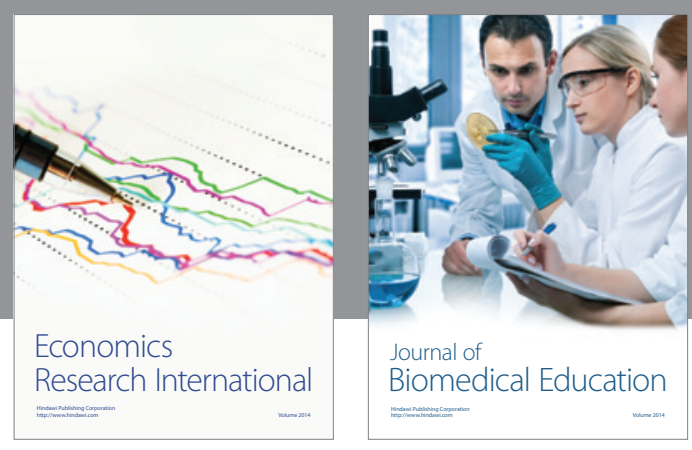

Journal of

Biomedical Education

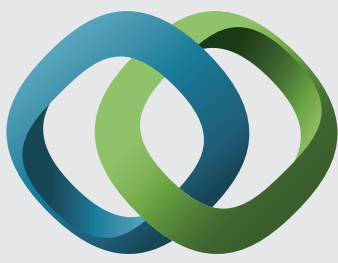

\section{Hindawi}

Submit your manuscripts at

http://www.hindawi.com
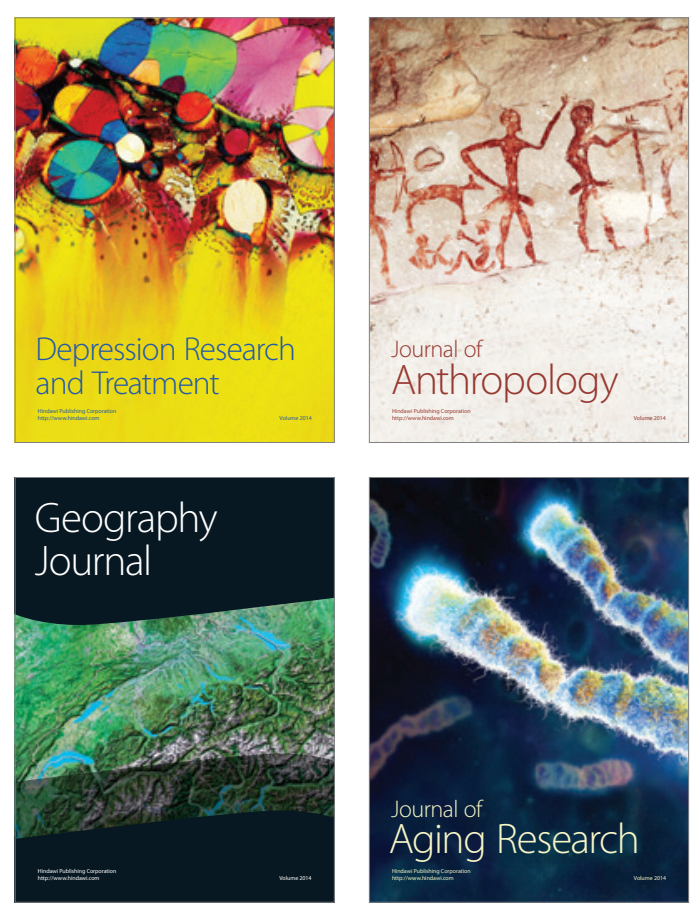

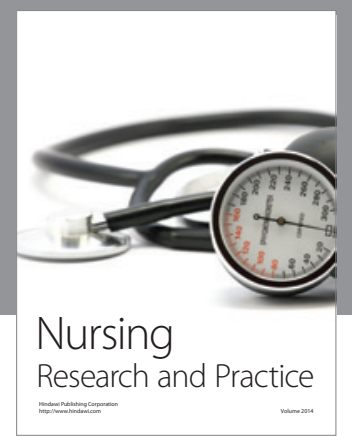

Nursing

Research and Practice

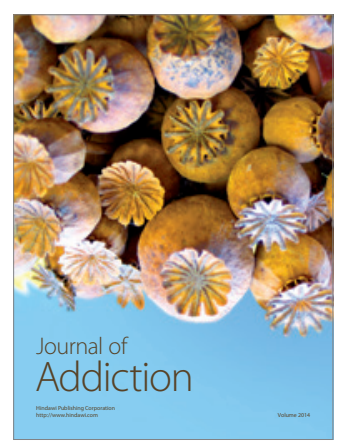

Child Development

Research

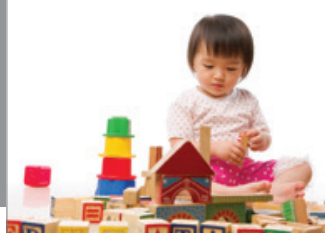

迥
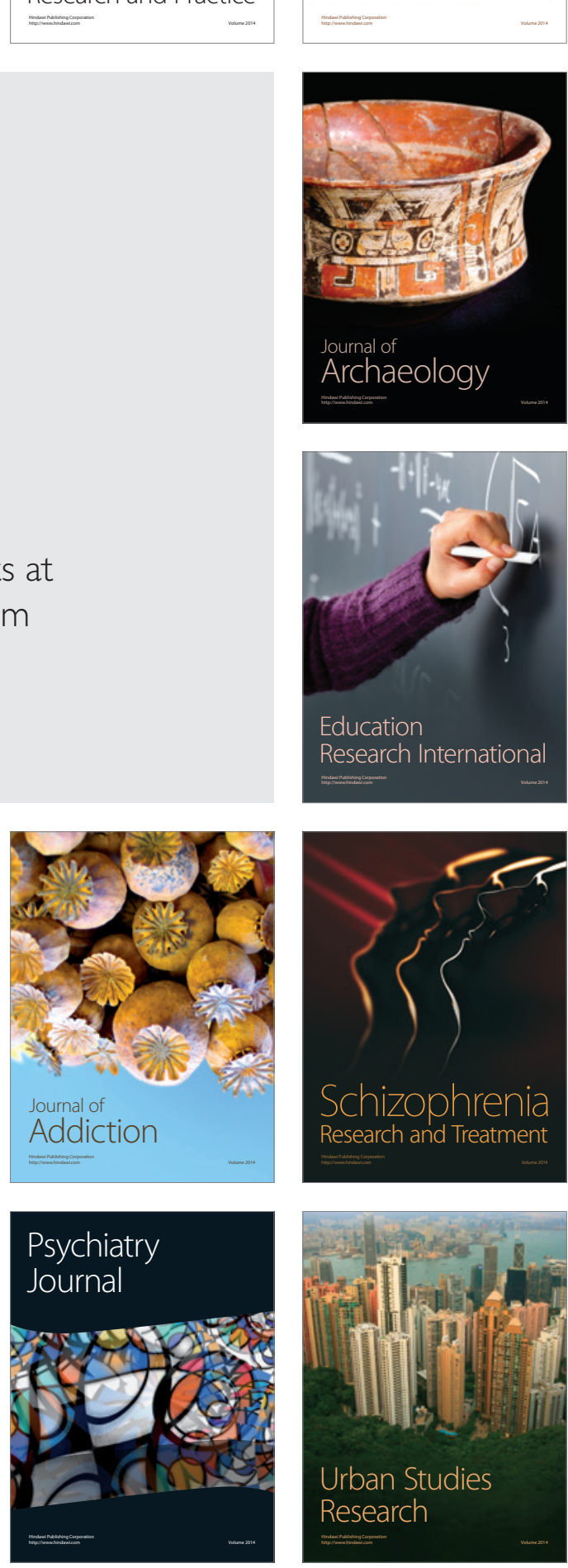